\title{
Protection of dried probiotic bacteria from bile using bile adsorbent resins
}

Article

Accepted Version

Mahbubani, K. T., Slater, N. K. H. and Edwards, A. D. (2014) Protection of dried probiotic bacteria from bile using bile adsorbent resins. New Biotechnology, 31 (1). pp. 69-72. ISSN 1871-6784 doi: https://doi.org/10.1016/j.nbt.2013.09.001 Available at https://centaur.reading.ac.uk/35887/

It is advisable to refer to the publisher's version if you intend to cite from the work. See Guidance on citing.

To link to this article DOI: http://dx.doi.org/10.1016/j.nbt.2013.09.001

Publisher: Elsevier

All outputs in CentAUR are protected by Intellectual Property Rights law, including copyright law. Copyright and IPR is retained by the creators or other copyright holders. Terms and conditions for use of this material are defined in the End User Agreement.

\section{www.reading.ac.uk/centaur}

\section{CentAUR}

Central Archive at the University of Reading

Reading's research outputs online 


\title{
Protection of Dried Probiotic Bacteria from Bile using Bile Adsorbent Resins
}

\author{
Krishnaa T. Mahbubani ${ }^{1}$, Nigel K. H. Slater ${ }^{+1}$, and Alexander D. Edwards ${ }^{*}{ }^{2}$ \\ ${ }^{1}$ Department of Chemical Engineering and Biotechnology, University of Cambridge, New \\ Museums Site, Pembroke Street, Cambridge CB2 3RA, UK. \\ ${ }^{2}$ Reading School of Pharmacy, Whiteknights, PO Box 224, Reading, RG6 6AD, UK. \\ *CORRESPONDING AUTHOR: \\ Email: a.d.edwards@ reading.ac.uk \\ Telephone: +44 (0) 118378 4253, Fax +44 (0) 1183784703 \\ ${ }^{+}$CORRESPONDING AUTHOR: \\ Email: nkhs2@cam.ac.uk \\ Telephone: +44 (0)1223 762953, Fax +44 (0) 1223762
}

\section{Running title:}

Cholestyramine Protects Dried Lactobacillus Casei from Bile

\begin{abstract}
Enteric coated oral tablets or capsules can deliver dried live cells directly into the intestine.

Previously, we found that a live attenuated bacterial vaccine acquired sensitivity to intestinal bile when dried, raising the possibility that although gastric acid can be bypassed, significant loss of viability might occur on release from an enteric coated oral formulations. Here we demonstrate that some food-grade lyophilised preparations of Lactobacillus casei and Lactobacillus salivarius also show temporary bile sensitivity that can be rapidly reversed by rehydration. To protect dried cells from temporary bile sensitivity, we propose using bile acid adsorbing resins, such as cholestyramine, which are bile acid binding agents, historically used to lower cholesterol levels. Vcaps $^{\mathrm{TM}}$ HPMC capsules alone provided up to 830 -fold protection from bile. The inclusion of


$50 \%$ w/w cholestyramine in Vcaps ${ }^{\mathrm{TM}}$ HPMC capsules resulted in release of up to 1700-fold more live Lactobacillus casei into simulated intestinal fluid containing $1 \%$ bile, when compared to dried cells added directly to bile. We conclude that delivery of dried live probiotic organisms to the intestine may be improved by providing protection from bile by addition of bile adsorbing resins and the use of HPMC capsules.

\section{Highlights}

-When dispersed in bile at intestinal concentrations some dried probiotic bacteria are killed -Bile toxicity can be blocked using the bile adsorbing resin cholestyramine -Formulation with bile adsorbants may protect dried probiotic bacteria from intestinal bile -Some hard shell capsules can alone provide protection from bile

\section{KEYWORDS}

Probiotic bacteria, bile adsorbing resin, cholestyramine, bile, oral delivery

\section{ABBREVIATIONS}

BAR, bile acid adsorbing resin. LAB, lactic acid bacteria. LBV, live bacterial vaccine. HPMC, hydroxyl methyl cellulose.

\section{Introduction}

Live bacteria are administered orally for a range of therapeutic applications, ranging from live oral attenuated enteric pathogens used as vaccines to commensal bacteria administered in foods such as yoghurt. Therapeutic live bacteria represent a major delivery challenge for pharmaceutical scientists, presenting problems with maintaining viability during manufacture and storage, as well as difficulty in producing oral formulations due to sensitivity to moisture, temperature and pressure. Once an oral formulationcontaining live stabilised bacteria has been manufactured, there remains one final major delivery challenge: to maintain bacterial viability after oral administration and survive the harsh microbicidal conditions encountered in the gastrointestinal tract.

A wide range of live microbes, termed probiotics, have been proposed to confer a broad range of therapeutic benefits when administered orally. These benefits range from re-colonisation of the gut after antibiotic treatment to reduce the severity of diarrhoea [1], beneficial modification 
of gut metabolism [2], suppression of intestinal inflammation [3], and when genetically modified, for delivery of biopharmaceuticals in situ [4]. Although many formulations have been developed for oral delivery of live bacteria ranging from exotic functional foods such as confectionary to traditional dairy products such as yoghurt [5], solid dosage forms such as capsules or tablets containing dried live probiotic bacteria offer the most control of both dose and site of delivery and drying also increases shelf life and stability.

For effective function, it is essential for live organisms to overcome the highly efficient microbicidal barriers present in the human gastrointestinal tract. Gastric acid, which is sterilising to all but the most robust microbe, can be avoided by coating the dose with acid-insoluble enteric polymers. However, dried live probiotic cells released from enteric coated oral doses are then exposed to intestinal bile acids, the major component of bile secreted from the gall bladder. Although the main function of bile acids is as a detergent to solubilise dietary lipids, many microbes are intolerant of detergents and bile represents a major microbicidal barrier to survival of probiotic bacteria [6]. Indeed, bile tolerance is a major factor considered when bacterial strains are selected as candidate probiotics [7].

An additional challenge is faced when live bacteria are dried, because cell injury caused during drying can increase the sensitivity of bacteria to microbicides; for example transient cell wall damage can occur after freezing which allows detergents such as bile acids to kill cells [8]. We found that even a highly bile resistant live attenuated bacterial vaccine (LBV) strain of Salmonella typhimurium became sensitive to moderate bile concentrations [9]. The degree of bile sensitivity observed for dried cells depends on a number of factors including the culture conditions and growth stage prior to drying, and on the drying method and excipient used ([9] and unpublished observations). Importantly, with highly bile adapted enteric organisms such as Salmonella, this temporary bile sensitivity is reversed very rapidly - i.e. within minutes - after rehydration $[8,10]$. Having discovered this temporary increased sensitivity of LBV to bile after drying, we developed a simple formulation that protects transiently bile sensitive dried LBV by temporary bile acid adsorption using bile acid adsorbing resins (BAR) [9-11].

In the current study we ask two further questions. Firstly, is drying-induced temporary bile senstivity restricted to LBV dried in the laboratory, or do dried lactic acid bacteria (LAB) produced as human food supplements also exhibit increased bile sensitivity after drying? Secondly, is it possible that BAR can be utilised to protect dried LAB from bile in a simple oral formulation suitable for delivery of probiotics? 


\section{Materials and Methods}

MRS agar, dried pig and ox bile, cholestyramine, and microcrystalline cellulose (MCC, Avicel PH 101) were obtained from Sigma Aldrich (Dorset, UK). Simulated intestinal fluid was Phosphate Standard Buffer specified by the International Pharmacopeia as $0.025 \mathrm{M}$ potassium dihydrogen phosphate and $0.025 \mathrm{M}$ di-sodium hydrogen phosphate at pH6.8, and where indicated dried pig or ox bile was dissolved followed by filtration. Capsules were size $00 \mathrm{Vcaps}^{\mathrm{TM}}$ HPMC capsules supplied by Capsugel (Bornhem Belgium). Powders containing the lactic acid bacteria Lactobacillus casei strain UALC-03; Lactobacillus acidophilus strain DDS-1; Lactobacillus salivarius strain UALS-07 were commercially manufactured through a fermentation process and freeze-drying by UAS labs (Minnesota, USA). Strain identity was confirmed and powders screened for pathogens by the manufacturer; the powder was supplied as a food supplement suitable for human consumption.

To test the bile sensitivity of dried and rehydrated bacteria, individually weighed samples were placed in $50 \mathrm{ml}$ test tubes, and $25 \mathrm{ml}$ of simulated intestinal fluid with or without $1 \%$ pig bile were added, followed by incubation at $37^{\circ} \mathrm{C}$ and sampling live cell numbers at 1 and 2 hours. In some cases, the LAB powder was firstly rehydrated in $12.5 \mathrm{ml}$ simulated intestinal fluid without bile for $1 \mathrm{~h}$, followed by dilution with $12.5 \mathrm{ml} 2 \%$ pig bile, such that the final bile concentration was identical to the sample directly exposed to bile.

To test protection provided by different formulations against bile toxicity, $L$. casei powder was mixed either with MCC filler alone or a mixture of MCC and cholestyramine, and size 00 Vcaps $^{\mathrm{TM}}$ HPMC capsules (Capsugel, Bornem Belgium) were filled with approximately $300 \mathrm{mg}$ powder, of which $13-15 \% \mathrm{w} / \mathrm{w}$ of capsule content was L. casei powder corresponding to 39-45mg per capsule, and 50\% w/w was cholestyramine (where added). Capsules were filled by hand using a Cap-M-Quick (Value Healthcare, Rotherham, UK), and fitted into a wire sinker. Individual capsules were weighed and added to $50 \mathrm{ml}$ tubes containing $25 \mathrm{ml}$ of simulated intestinal fluid alone or with the indicated concentrations of ox or pig bile, and incubated for $1 \mathrm{~h}$ at $37^{\circ} \mathrm{C}$, followed by sampling to determine live cell numbers.

To measure live cell numbers, cells and residual excipients were thoroughly resuspended, samples were taken at the stated times and serially 4-fold diluted in phosphate buffer in sterile 96well microwell plates. Replicate 10ul portions of the diluted cells were plated as spots on MRS agar, followed by incubation at $37^{\circ} \mathrm{C}$ for $48-72 \mathrm{~h}$. Colony forming units (CFU) were counted, and 
the equivalent viable cell recovery per weight of initial LAB powder was then calculated based on the dilution and volumes used.

\section{Results}

\section{Transient bile sensitivity in lyophilised LAB powders}

Initial experiments focussed on determining if commercially manufactured, food grade dried LAB display the same temporary increased bile sensitivity seen when LBV were dried in the laboratory. Samples of lyophilised powders of a range of different LAB were tested by comparing viable cell recovery in three conditions: after rehydration in buffer for 1 and $2 \mathrm{~h}$; after direct exposure to a $1 \%$ ox bile solution for 1 and $2 \mathrm{~h}$; and finally after rehydration and recovery for $1 \mathrm{~h}$ in buffer, followed by switching to a $1 \%$ ox bile solution for a further $1 \mathrm{~h}$ incubation.

Two distinct patterns of viable cell recovery were observed, depending on the LAB powder tested. In some cases, illustrated here by preparations of L. casei and L. salivarius, dried cells were more bile sensitive than after rehydration. Direct exposure to bile gave very high loss of viability, but far lower losses were found when rehydrated in buffer followed by bile exposure. When directly exposed to $1 \%$ bile, a preparation of $L$. casei showed $10^{3}$-fold loss at $1 \mathrm{~h}$, and $L$. salivarius showed $>10^{5}$-fold loss by $1 \mathrm{~h}$, compared to dissolution in buffer alone. In contrast, when these preparations were first rehydrated for $1 \mathrm{~h}$ in buffer followed by $1 \mathrm{~h}$ exposure to bile, less than 100-fold loss of viable cell recovery was observed (Fig. 1).

With other dried LAB powders, illustrated here by a preparation of L. acidophilus, no difference in bile sensitivity was seen regardless of whether the powder was directly exposed to bile or rehydrated first, suggesting these particular strains or preparations may have intrinsic rather than drying-induced - bile sensitivity (Fig. 1). With the preparation of L. acidophilus, little toxicity was seen after $1 \mathrm{~h}$ exposure to bile, and approximately 100 -fold loss of viability was seen after either $2 \mathrm{~h}$ exposure bile or buffer followed by bile (Fig. 1).

\section{Protection from bile toxicity using BAR in capsules}

To overcome temporary bile toxicity, a bile binding agent such as the BAR cholestyramine can simply be mixed with dried LBV to temporarily adsorb bile acids and allow bile resistance to recover $[10,11]$. Furthermore, capsules made from hydroxymethylpropyl cellulose (HPMC), a vegetarian alternative to hard gelatine shells, can confer a significant degree of bile protection to dried LBV without addition of BAR [11]. We tested if Vcaps ${ }^{\mathrm{TM}}$ HPMC capsules alone, or an optimised formulation with cholestyramine Vcaps ${ }^{\mathrm{TM}}$ HPMC capsules could 5 
also confer protection from bile to dried LAB. Two concentrations of ox bile and pig bile were compared, since differences in bile acid composition can affect toxicity [6].

When L. casei powder was mixed with filler alone and filled into Vcaps ${ }^{\mathrm{TM}}$ HPMC capsules, dissolution in bile solutions resulted in a dose-dependent loss in viable cell recovery after $1 \mathrm{~h}$ incubation (Fig. 2). The bile toxicity seen with $L$. casei filled in Vcaps ${ }^{\mathrm{TM}}$ HPMC capsules (Fig. 2) was significantly lower than that observed when L. casei powder was exposed directly to $1 \%$ pig-bile (Fig. 1), suggesting that capsules alone provide some protection from bile. However, when the BAR cholestyramine was included within the capsule, minimal reduction in live cell recovery was seen at all concentrations of bile tested. This demonstrates that formulation of dried $\mathrm{LAB}$ with BAR in capsules effectively protects cells from temporary bile toxicity, as found previously with LBV.

\section{Discussion}

Four methods have previously been explored for protecting beneficial probiotic bacteria from bile toxicity after oral administration. Firstly, probiotic strains can be selected for increased bile resistance [7]. Secondly, bacteria can be adapted by culture conditioning for example by addition of detergents to media during fermentation, resulting in increased bile resistance [12, 13]. Thirdly, a wide range of microencapsulation technologies have been developed to produce micro formulated probiotic preparations with increased acid and bile sensitivity [2, 14]. Lastly, for advanced therapies using engineered strains to produce biopharmaceuticals in situ in the gut, genetic modification to confer increased bile resistance has been explored [15, 16].

We propose a new, simpler method, specifically for situations where increased toxicity is seen for dried probiotic powder when compared to previously hydrated cells in liquid culture. A simple oral dose form, such as a capsule, is filled with a BAR such as cholestyramine mixed with dried probiotic cells and enteric coated to provide protection from gastric acid; this coating dissolves as the $\mathrm{pH}$ rises in the duodenum, resulting in release of dried cells directly into the upper small intestine. When the enteric coating is dissolved and the capsule contents hydrated by intestinal fluids, bile acids are temporarily bound by BAR, and the dried bacteria are rehydrated giving time for recovery of bile resistance. Since cholestyramine is manufactured as a generic on a large scale, and has a long history of safe use, their inclusion as an additional excipient should not significantly add to the cost or ease of regulatory approval of an oral probiotic medicine.

In this simple in vitro study, $1 \mathrm{~h}$ incubation of dried $L$. casei powder in $1 \%$ pig bile released 3,500-fold fewer live cells than buffer alone (Fig. 1); in contrast when the same powder 
was filled into capsules with cholestyramine, only 2-fold fewer live cells were recovered (Fig. 2), representing a 1700-fold protection from bile. Note that the protection seen by inclusion of BAR within HPMC capsules cannot simply be accounted for by bulk depletion of the solution of bile acids. $150 \mathrm{mg}$ of cholestyramine has a capacity to bind a maximum of 570 $\mu$ mole bile acids [17], yet $25 \mathrm{ml} 4 \%$ bile solution contains $2500 \mu$ mole bile acids. Therefore protection is provided against >4-fold excess of bile acids. We proposed a mechanism for protection that suggests that temporary depletion of bile acids occurs in the hydrating oral dose form containing BAR [11]. The dried bacteria rehydrate and recover bile resistance, followed by release into the bulk bile solution.

Surprisingly, Vcaps ${ }^{\mathrm{TM}}$ HPMC capsules alone provide significant protection of dried LAB from bile, when compared to dispersing powder directly into bile solutions (Figs. 1 and 2). Previously, we found that depending on the capsule shell material, simply filling dried LBV powder into capsules prior to exposure to bile solutions give significant protection from bile toxicity compared to powder dispersed directly into bile, with Vcaps ${ }^{\mathrm{TM}}$ HPMC capsules giving the best protection and alone able to confer 860 -fold protection from $1 \%$ bile for dried $S$. typhimurium [11]. We suggested this might be due to the capsule shell material forming a gel that retards bile acid entry and protects cells during dissolution: different shell polymers have varying intrinsic gel stability and bile acid binding potential, hence the variation in protection afforded by different capsule types. This protection was also observed with L. casei powder, with 830-fold protection from bile provided by Vcaps ${ }^{\mathrm{TM}}$ HPMC capsules alone (Figs. 1 and 2). In spite of this capsule-intrinsic protection, the best protection was afforded by inclusion of BAR, which gave an additional 3.1-fold protection over capsules alone (Fig. 2).

This initial study suggests that the inclusion of BAR and use of HPMC capsules, in addition to enteric coating, offer possible benefits for delivery of dried LAB as therapeutic probiotics. Further research is needed to understand why some, but not all, food grade dried LAB preparations show temporary bile sensitivity. The formulation can be further tested in advanced in vitro gut models to confirm that the improved viability seen here in bile solutions is replicated in more accurately simulated intestinal conditions. In vivo delivery studies in suitable animal models such as pigs (large monogastric mammal with similar gastrointestinal conditions to humans) are also required to test if the improved viability in in vitro simulated intestinal conditions translates into an increase in live bacterial cell delivery to the intestine. Ulitmately clinical studies are vital to determine if improving delivery efficacy using advanced formulations of live bacteria can deliver therapeutic benefits. 


\section{ACKNOWLEDGMENTS}

Powders of freeze-dried probiotic LAB were kindly provided by Dr SK Das from UAS laboratories. Information on capsule use and samples of Vcaps ${ }^{\mathrm{TM}}$ were kindly provided by Capsugel. ADE and KTM are grateful to the Technology Strategy Board and the EPSRC for financial support of this work. We thank Chris Arnot for helpful comments on the manuscript.

\section{FIGURE CAPTIONS}

Figure 1. Bile sensitivity of dried and rehydrated lactobacillus preparations. The bile sensitivity of different preparations of dried LAB was measured either when exposed to bile solutions directly as a dried powder or after hydration for $1 \mathrm{~h}$ in phosphate buffer. Bars indicate the mean of 4-6 replicate samples and error bars indicate 1 standard deviation. Similar bile sensitivity was observed in at least 2 replicate experiments with each probiotic preparation.

Figure 2. Protecting dried L. casei from transient bile sensitivity using the BAR cholestyramine. Dried LAB powders were either filled into Vcaps ${ }^{\mathrm{TM}}$ HPMC capsules alone or with cholestyramine, and capsules added to buffer or bile solutions for $1 \mathrm{~h}$, followed by live cell determination. Bars indicate the mean of 4-6 replicate samples and error bars indicate 1 standard deviation. Similar results were obtained in at least 2 replicate experiments.

\section{REFERENCES plain text without journal issue number.}

1. Bergogne-Berezin, E., Treatment and prevention of antibiotic associated diarrhea. Int J Antimicrob Agents, 2000. v16 p. 521-6.

2. Prakash, S. and C. Martoni, Toward a new generation of therapeutics: artificial cell targeted delivery of live cells for therapy. Appl Biochem Biotechnol, 2006. v128 p. 1-22.

3. Bohm, S.K. and W. Kruis, Probiotics: do they help to control intestinal inflammation? Ann N Y Acad Sci, 2006. v1072 p. 339-50.

4. Steidler, L., S. Neirynck, N. Huyghebaert, et al., Biological containment of genetically modified Lactococcus lactis for intestinal delivery of human interleukin 10. Nat Biotechnol, 2003.v 21 p. 785-9.

5. Granato, D., G.F. Branco, F. Nazzaro, et al., Functional Foods and Nondairy Probiotic Food Development: Trends, Concepts, and Products. Comprehensive Reviews in Food Science and Food Safety, 2010. v9 p. 292-302. 
6. Begley, M., C.G. Gahan, and C. Hill, The interaction between bacteria and bile. FEMS Microbiol Rev, 2005. v29 p. 625-51.

7. Saarela, M., G. Mogensen, R. Fonden, et al., Probiotic bacteria: safety, functional and technological properties. J Biotechnol, 2000. v84 p. 197-215.

8. Ray, B., D.W. Janssen, and F.F. Busta, Characterization of the repair of injury induced by freezing Salmonella anatum. Appl Microbiol, 1972. v23 p. 803-9.

9. Edwards, A.D. and N.K. Slater, Formulation of a live bacterial vaccine for stable room temperature storage results in loss of acid, bile and bile salt resistance. Vaccine, 2008. v26 p. 5675-8.

10. Edwards, A.D. and N.K. Slater, Protection of live bacteria from bile acid toxicity using bile acid adsorbing resins. Vaccine, 2009. v27 p. 3897-903.

11. Edwards, A.D., P. Chatterjee, K.T. Mahbubani, et al., Optimal protection of stabilised dry live bacteria from bile toxicity in oral dosage forms by bile acid adsorbent resins. Chemical Engineering Science, 2010. v65 p. 4844-4854.

12. Kimoto, H., S. Ohmomo, and T. Okamoto, Enhancement of bile tolerance in lactococci by Tween 80. J Appl Microbiol, 2002. v92 p. 41-6.

13. van Velkinburgh, J.C. and J.S. Gunn, PhoP-PhoQ-Regulated Loci Are Required for Enhanced Bile Resistance in Salmonella spp. Infect. Immun., 1999. v67 p. 1614-1622.

14. Ding, W.K. and N.P. Shah, Acid, bile, and heat tolerance of free and microencapsulated probiotic bacteria. J Food Sci, 2007. v72 p. M446-50.

15. Watson, D., R.D. Sleator, C. Hill, and C.G. Gahan, Enhancing bile tolerance improves survival and persistence of Bifidobacterium and Lactococcus in the murine gastrointestinal tract. BMC Microbiol, 2008. v8 p. 176.

16. Termont, S., K. Vandenbroucke, D. Iserentant, et al., Intracellular accumulation of trehalose protects Lactococcus lactis from freeze-drying damage and bile toxicity and increases gastric acid resistance. Appl Environ Microbiol, 2006. v72 p. 7694-700.

17. Honda, Y. and M. Nakano, Studies on adsorption characteristics of bile acids and methotrexate to a new type of anion-exchange resin, colestimide. Chem Pharm Bull (Tokyo), 2000. v48 p. 978-81. 
Figure 1:

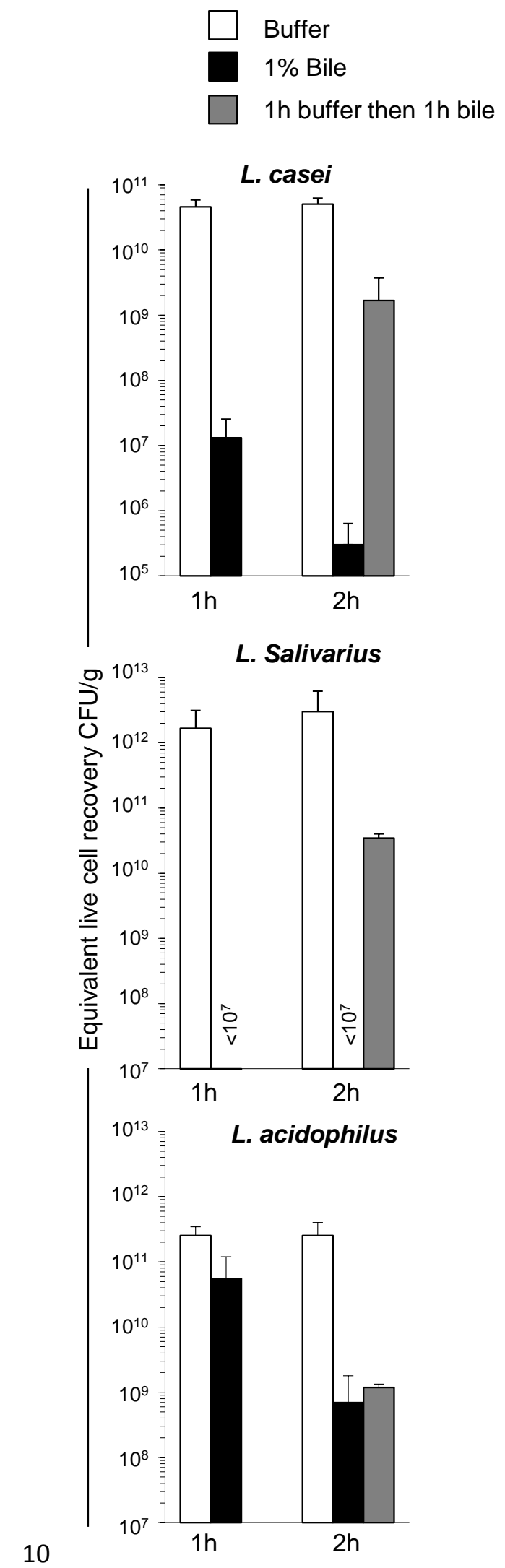




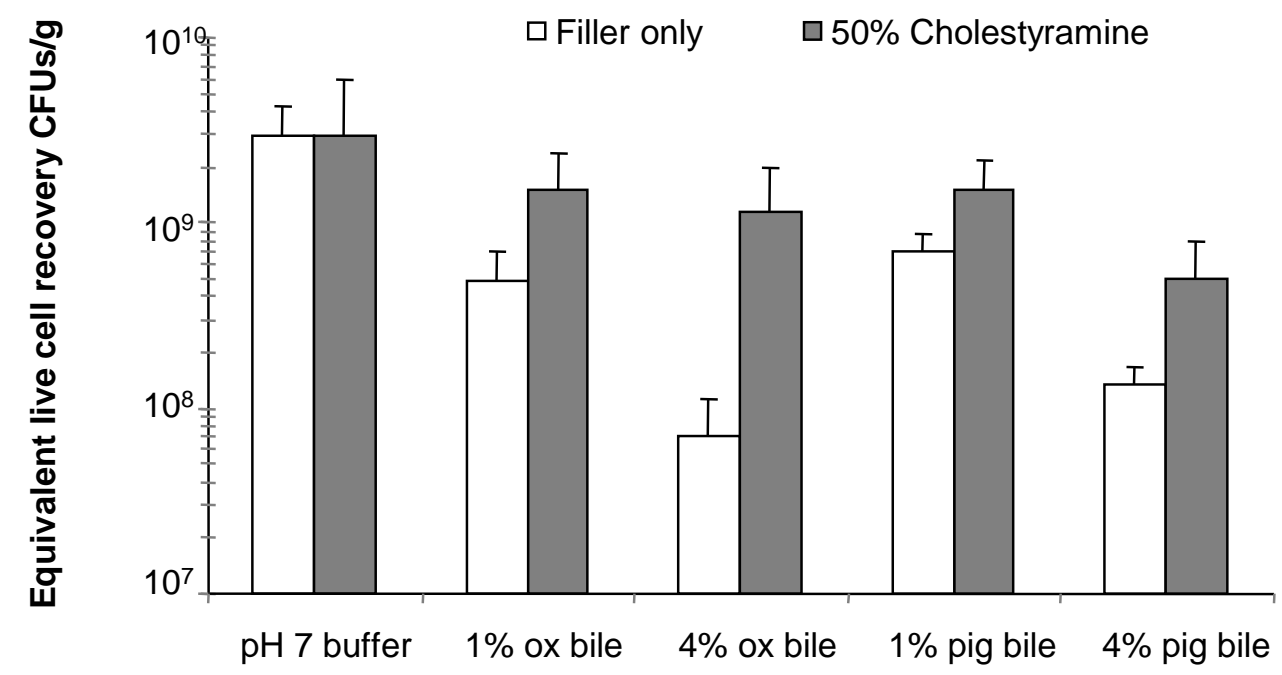

